\title{
Investigating the associations between intimate partner violence and nutritional status of women in Zimbabwe
}

Jeanette Mukamana

Africa University, Zimbabwe

Pamela Machakanja

Africa University, Zimbabwe

Hajo Zeeb

Leibniz Institute for Prevention Reseach and Epidemiology, BIPS Germany

Sanni Yaya

University of Ottawa

Nicholas Kofi Adjei ( $\nabla$ adjei@uni-bremen.de )

Universitat Bremen

Research article

Keywords: Intimate Partner Violence, Gender, Nutritional Status, Body Mass Index, Zimbabwe

Posted Date: September 10th, 2020

DOI: https://doi.org/10.21203/rs.3.rs-56101/v1

License: (9) This work is licensed under a Creative Commons Attribution 4.0 International License.

Read Full License 


\section{Abstract}

Background: Intimate partner violence (IPV) against women and poor nutritional status are growing health problems in low and middle-income countries (LMICs). Moreover, violence against women has been shown to be associated with poor nutrition. This study investigated the relationship between IPV and nutritional status (i.e., underweight, overweight, and obesity) among women of reproductive age (1549 years) in Zimbabwe.

Methods: Pooled data from the 2005/2006, 2010/2011, and 2015 Zimbabwe Demographic Health Surveys (ZDHS) on 13,008 married/cohabiting women were analysed. Multinomial logistic regression models were used to examine the associations between the various forms of IPV and the nutritional status of women. We further estimated the prevalence of $\mathrm{BMI} \geq 25.0 \mathrm{~kg} / \mathrm{m}^{2}$ (overweight and obesity) by intimate partner violence type.

Results: The mean BMI of women was $24.3 \mathrm{~kg} / \mathrm{m}^{2}$, more than one-fifth (24\%) were overweight and about $12 \%$ were obese. Forty-three percent $(43 \%)$ of women reported to have ever experienced at least one form of intimate partner violence. More than one-third (35\%) of women who reported to have ever experienced at least one form of intimate partner violence had a BMI $\geq 25.0 \mathrm{~kg} / \mathrm{m}^{2}(\mathrm{p}<0.01)$. Relative to normal weight, women who had ever experienced at least one form of IPV (i.e., physical, emotional, or sexual) were more likely to be obese $(\mathrm{aOR}=2.59 ; 95 \% \mathrm{Cl}=1.05-6.39)$. Women's exposure to any form of intimate partner violence was not significantly associated with the likelihood of being underweight or overweight relative to normal weight.

Conclusions: The study findings showed that women of reproductive age in Zimbabwe are at high risk of both IPV and excess weight. Moreover, we found a positive relationship between IPV and obesity. Public health interventions that target the well-being, empowerment, and development of women are needed to address the complex issue of IPV and adverse health outcomes, including obesity.

\section{Introduction}

Intimate partner violence (IPV) is a form of gender-based violence [1], mostly perpetrated against women $[2,3]$. This behaviour is assaultive and coercive $[4,5]$, and it comes in the form of emotional, sexual, or physical abuse [6-9]. The various forms of abuse may co-exist [10]; for instance, physical abuse or violence is mostly accompanied by sexual violence, and the latter may also come along with emotional violence $[10,11]$. IPV is increasingly recognized as a relevant social and health problem by relevant institutions and organizations worldwide [12-14], due to its adverse impacts on victims [10,15], and society as a whole [7, 16-19].

Violence against women as a health problem $[16,17]$ has been shown to be one of the leading causes of both medical diagnosed and non-medical explainable physical, mental, and gynecological health problems [7, 20-23]. Also, it remains a symptom of gendered power relations [24, 25], which may be a 
predictor of women's health [26,27], including stressful conditions [24, 28], and nutritional status such as underweight, overweight and obesity [18].

The issue of obesity is becoming a worldwide problem [29], increasingly also in developing countries [30]. In Sub Saharan Africa, the prevalence of overweight and obesity has been rising at an alarming rate [31], and women are the most affected [31]. Globally, overweight and obesity among female adults have increased from 29.8-38.0\% between 1980 and 2013 respectively [32], with a recent study conducted in Zimbabwe [33] confirming these findings for the time period 2005 to 2015. Differences in experiencing obesity and overweight among socioeconomic subgroups [34] may be linked to IPV in complex ways. For example, prior evidence suggests that abused women may end up suffering from depression [35], and may hence seek consolation in overeating [36]. In rich food environments, they tend to consume energydense foods [37], which has been shown to be a risk factor for obesity [18, 37]. Furthermore, there is evidence that physical and sexual violence against women may predict excessive weight gain and poor nutrition [38, 39], where some abused women tend to suffer from high stress-induced metabolisms, depression, loss of appetite with limited caloric intake [40,41]. The stress suffered by abused women has been shown to increase oxidative stress and metabolic levels [41, 42], which are also risk factors for anemia and underweight [26, 35]. IPV thus contributes to the risk of poor nutrition outcomes, especially where abusive male partners withhold food as a form of punishment to their female partners [43].

From the above discussions, it is clear from the literature that there is an relationship between IPV and women's health $[44,45]$. While some studies have examined the relationship between dietary knowledge, the attitude of behaviours, socio-demographic factors and IPV [18, 27, 46, 47], no study has investigated the association between IPV and the nutritional status of woman in Zimbabwe. This study, therefore, sought to explore the relationship between IPV and nutritional status (i.e., underweight, overweight, and obesity) among women of reproductive age Zimbabwe.

\section{Materials And Methods}

\section{Data}

The analysis was based on pooled data of married/cohabiting women from the 2005/2006, 2010/2011, and 2015 Zimbabwe Demographic Health Surveys. The surveys were conducted by the Zimbabwe National Statistical Agency in collaboration with other international organizations, and they were nationally representative surveys of men and women in their reproductive age. The surveys employed a two-stage stratified cluster sampling technique based on census enumeration areas (EAs) and household samples in both rural and urban areas. The first stage was the selection of EAs with probability proportional to the size and the second stage involved household sampling. The analysis was limited to non-pregnant women of reproductive age with valid weight and height measurements. Pregnant women were excluded to avoid a misleading picture of the issue of overweight and obesity during pregnancy [33]. The samples after the exclusion were (survey year: 2005/2006; $n=4,031$ ), (survey year: 2010/2011; $n=$ $4,211)$ and (survey year: $2015 ; n=4,766)$, with a pooled total $(N=13,008)$ for the final analysis. 


\section{Measurement of the outcome variable}

The outcome variable for this study was the nutritional status of women (that is, underweight, normal weight, overweight, and obesity). The body mass index (BMl; weight $(\mathrm{kg}) /$ height $(\mathrm{m})$ squared) was used to assess the nutritional status of women [48], and it is commonly used to classify underweight, overweight and obesity in adults $[49,50]$. Respondents were classified according to the BMI criteria of the World Health Organisation (WHO): a) underweight, $\mathrm{BMI}<18.5 \mathrm{~kg} / \mathrm{m}^{2} ; \mathrm{b}$ ) normal weight, $\mathrm{BMI}$ of $18.5-$ $24.9 \mathrm{~kg} / \mathrm{m}^{2}$; c) overweight, BMI of $25.0-29.9 \mathrm{~kg} / \mathrm{m}^{2}$ and d) obesity, $\mathrm{BMI} \geq 30.0 \mathrm{~kg} / \mathrm{m}^{2}$ [51]. In the surveys, participants' standing heights were measured using a measuring board and their weights were taken using the United Nations Children's Fund (UNICEF) electronic scale with a digital display.

\section{Independent variables}

The outcome variable in this study was IPV. The measurement of IPV in the surveys was based on the Revised Conflict Tactics (CTs) [52] and was administered following standard guidelines for research on domestic violence set by the World Health Organisation [53]. The questions posed to women included "did your husband/partner ever: slap, push, shake, punch, beat, kick or try to strangle you, throw something at you, threaten you using a harmful object?" These questions were used to derive physical violence. Sexual violence was assessed by the questions "did your husband/partner ever: physically force you to have sexual intercourse even when you did not want? Or force you with threats to perform any sexual acts you did not want?" Psychological violence was assessed using questions such as "did your husband/partner humiliate you in front of others, threaten to hurt you or those close to you with harm?". Responses were categorized as physical, emotional, sexual, physical or emotional, physical or sexual, emotional or sexual, and physical, sexual or emotional. Answers in the affirmative were coded as " 1 ", while women who never experienced any of the aforementioned forms of IPV was coded as "0".

\section{Socioeconomic controls}

In the adjusted regression models, we controlled for the following socio-demographic and economic variables: age (15-29, 20-24, 25-29, 30-34, 35-39, 40+); marital status (married, cohabiting); place of residency (rural, urban), educational level (no education, primary, secondary and higher); parity $(<2,2-3$, 4-5, 6+); employment status (not currently employed, currently employed); and wealth index (poorest, poorer, middle, richer). All the variables were obtained from either the individual women's or the household questionnaires.

\section{Statistical Analysis}

First, basic descriptive statistics were performed to obtain the mean, frequency and percentages of the dependent, independent and some control variables. Second, percentages (\%) were used to describe the prevalence of $\mathrm{BMI} \geq 25.0 \mathrm{~kg} / \mathrm{m}^{2}$ (overweight and obesity) and the various forms of IPV. Differences in prevalence were examined using chi-square test. Third, we estimated the prevalence of IPV among women who experienced at least one type of abuse (i.e. physical, sexual or emotional) by nutritional 
status (underweight, normal weight, overweight and obese). In the second part of the analysis, multinomial logistic regression models were used to examine the associations between the various forms of IPV and the nutritional status of women. The prevalence and adjusted odd ratios (aOR) with 95\% confidence intervals $(95 \% \mathrm{Cl})$ was calculated using Stata Version 14 (Stata Corp, College Station, Texas, USA). The dataset was weighted to account for differences in the sampling design.

\section{Results}

\section{Distribution of selected characteristics}

The distribution of respondents' characteristics is shown in Table 1. Overall, the mean age of women was approximately 30 years. Most women (64\%) reported having secondary or higher education. On average, women had three live births, and about $67 \%$ lived in rural areas. Regarding economic status, more than half $(61 \%)$ were not in paid employment, and $41 \%$ reported middle economic class. 
Table 1

Percentage distribution of the characteristics of women (15-49 years) in Zimbabwe, pooled data, $2005-2015(n=13,008)$

\begin{tabular}{|c|c|}
\hline Variables & $\%$ \\
\hline \multicolumn{2}{|l|}{ Anthropometry } \\
\hline \multicolumn{2}{|l|}{$\mathrm{BMI}(\mathrm{Kg} / \mathrm{m} 2)($ Mean $=24.31 ; \mathrm{SD}=4.64)$} \\
\hline Underweight, or $\mathrm{BMI}<18.5$ & 5.11 \\
\hline Normal weight, or $\mathrm{BMI} 18.5 \leq \mathrm{BMI}<25$ & 59.45 \\
\hline Overweight, or $25 \leq \mathrm{BMl}<30$ & 23.59 \\
\hline Obese, or $\mathrm{BMI} \geq 30$ & 11.85 \\
\hline \multicolumn{2}{|l|}{ Intimate Partner Violence, by type } \\
\hline \multicolumn{2}{|l|}{ Physical } \\
\hline Ever & 28.18 \\
\hline Never & 71.82 \\
\hline \multicolumn{2}{|l|}{ Emotional } \\
\hline Ever & 28.06 \\
\hline Never & 71.94 \\
\hline \multicolumn{2}{|l|}{ Sexual } \\
\hline Ever & 12.60 \\
\hline Never & 87.40 \\
\hline \multicolumn{2}{|l|}{ Physical or Emotional } \\
\hline Ever & 40.12 \\
\hline Never & 59.88 \\
\hline \multicolumn{2}{|l|}{ Physical or Sexual } \\
\hline Ever & 33.29 \\
\hline Never & 66.71 \\
\hline \multicolumn{2}{|l|}{ Emotional or Sexual } \\
\hline Ever & 33.03 \\
\hline Never & 66.97 \\
\hline
\end{tabular}




\begin{tabular}{|c|c|}
\hline Variables & $\%$ \\
\hline Ever & 43.17 \\
\hline Never & 56.83 \\
\hline \multicolumn{2}{|c|}{ Sociodemographic controls } \\
\hline \multicolumn{2}{|c|}{ Age $($ Mean $=30.36 ; S D=7.96)$} \\
\hline $15-19$ & 6.33 \\
\hline $20-24$ & 20.73 \\
\hline $25-29$ & 23.35 \\
\hline $30-34$ & 20.29 \\
\hline $35-39$ & 13.65 \\
\hline $40+$ & 15.64 \\
\hline \multicolumn{2}{|l|}{ Marital Status } \\
\hline Married & 95.65 \\
\hline Cohabiting & 4.35 \\
\hline \multicolumn{2}{|l|}{ Parity } \\
\hline$<2$ & 25.68 \\
\hline $2-3$ & 45.20 \\
\hline $4-5$ & 20.53 \\
\hline $6+$ & 8.59 \\
\hline \multicolumn{2}{|l|}{ Place of residence } \\
\hline Urban & 33.36 \\
\hline Rural & 66.64 \\
\hline \multicolumn{2}{|l|}{ Educational Level } \\
\hline No education & 2.79 \\
\hline Primary & 33.29 \\
\hline Secondary and higher & 63.92 \\
\hline \multicolumn{2}{|l|}{ Employment Status } \\
\hline Not currently employed & 61.12 \\
\hline Currently employed & 38.88 \\
\hline
\end{tabular}




\begin{tabular}{|ll|}
\hline Variables & $\%$ \\
\hline Wealth (Index) & \\
\hline Poorest & 20.76 \\
\hline Poorer & 19.08 \\
\hline Middle & 41.47 \\
\hline Richer & 18.69 \\
\hline
\end{tabular}

The mean BMI of women was $24.3 \mathrm{~kg} / \mathrm{m}^{2}$ (Table 1). A high proportion of women had normal weight (59\%), more than one-fifth were overweight (24\%) and about $12 \%$ were obese. The results further showed that more than one-third (43\%) of women reported to have ever experienced at least one form of intimate partner violence, and large proportions ever experienced physical (28\%), emotional (28\%), and sexual (13\%) violence. More than one-third reported any physical or emotional violence (40\%) and any emotional or sexual violence (33\%). 
Table 2

Prevalence of $\mathrm{BMI} \geq 25.0 \mathrm{~kg} / \mathrm{m}^{2}$ (overweight and obesity) among women of reproductive age (15-49 years) by intimate partner violence type, Zimbabwe, pooled data, 2005-2015

\begin{tabular}{|c|c|c|}
\hline & $\mathrm{BMI} \geq 25 \mathrm{Kg} / \mathrm{m} 2(\%)$ & $P$ value* \\
\hline \multicolumn{3}{|l|}{ Intimate Partner Violence, by type } \\
\hline Physical & & $<0.001$ \\
\hline Ever & 31.86 & \\
\hline Never & 36.84 & \\
\hline Emotional & & 0.244 \\
\hline Ever & 34.66 & \\
\hline Never & 35.75 & \\
\hline Sexual & & $<0.05$ \\
\hline Ever & 33.07 & \\
\hline Never & 35.78 & \\
\hline Physical or Emotional & & $<0.001$ \\
\hline Ever & 33.89 & \\
\hline Never & 36.62 & \\
\hline Physical or Sexual & & $<0.001$ \\
\hline Ever & 32.49 & \\
\hline Never & 36.91 & \\
\hline Emotional or Sexual & & $<0.05$ \\
\hline Ever & 34.08 & \\
\hline Never & 36.11 & \\
\hline Physical or Emotional or Sexual & & $<0.01$ \\
\hline Ever & 35.44 & \\
\hline Never & 36.62 & \\
\hline
\end{tabular}

In Table 2, the results of the prevalence of $\mathrm{BMI} \geq 25.0 \mathrm{~kg} / \mathrm{m}^{2}$ (overweight and obesity) by intimate partner violence type are shown. In general, more than one-third (35\%) of women who reported to have ever 
experienced at least one form of intimate partner violence (i.e., physical emotional or sexual) had a BMI $\geq 25.0 \mathrm{~kg} / \mathrm{m}^{2}(\mathrm{p}<0.01)$. Similarly, more than one-third of women who ever experienced sexual $(33 \%)$, any physical or emotional (34\%), and any physical or sexual (33\%) violence reported being overweight or obese. The prevalence of any form of intimate partner violence (i.e., physical, sexual, or emotional) was generally high (60\%) among women who had normal weight (Fig. 1).

\section{Multinomial Logistic regression}

The adjusted odd ratios (aOR) and 95\% confidence intervals for the associations between intimate partner violence and the nutritional status of women are shown in Table 3. The multinomial regression model estimated the relative risk ratios of the relationships between intimate partner violence and body mass index (BMI) comparing underweight, overweight, and obesity to normal weight. In the model, we adjusted for socioeconomic factors (categorical, as shown in Table 1) and other behavioural risk factors including smoking status (yes or no), alcohol consumption (yes or no) and media exposure (yes or no). 
Table 3

Multinomial logistic regression of the association between intimate partner violence and nutritional status of women (15-49 years), Zimbabwe, pooled data, 2005-2015

Underweight -

aOR(95\% Cl)
Overweight - aOR

$(95 \% \mathrm{Cl})$
Obese -aOR $(95 \%$

$\mathrm{Cl})$

\section{Intimate Partner Violence, by \\ type}

Physical

Never (ref)

1

1

1

Ever

$1.31(0.66-2.62)$

$0.93(0.65-1.32)$

$0.97(0.59-1.59)$

Emotional

Never (ref)

1

1

1

Ever

$1.41(0.61-2.14)$

$1.32(0.91-1.91)$

$2.22(1.16-4.13)$

Sexual

Never (ref)

1

1

1

Ever

$1.04(0.71-1.53)$

$1.14(0.91-1.44)$

$1.29(0.92-1.81)$

Physical or emotional

Never (ref)

Ever

1

1

1

$0.67(0.25-1.78)$

$0.83(0.48-1.42)$

$0.51(0.22-1.81)$

Physical or sexual

Never (ref)

1

1

1

Ever

$0.81(0.37-1.76)$

$0.92(0.61-1.37)$

$0.71(0.40-1.25)$

Emotional or sexual

Never (ref)

1

1

1

Ever

$0.78(0.38-1.59)$

$0.75(0.49-1.14)$

$0.37(0.18-0.73)$

Physical, emotional or sexual

Never (ref)

Ever
1

$1.87(0.64-5.43)$
1

$1.31(0.72-2.37)$
1

$2.59(1.05-6.39)$

Notes: aOR- adjusted Odd Ratio. Model adjusted for women's age, marital status, parity, place of residence, employment status, wealth, smoking status, alcohol consumption and media exposure. 
Results from Table 3 showed that women's exposure to any form of intimate partner violence was not significantly associated with the likelihood of being underweight or overweight relative to normal weight. However, women who had ever experienced at least one form of IPV (i.e., physical, emotional, or sexual) were more likely to be obese $(\mathrm{aOR}=2.59 ; 95 \% \mathrm{Cl}=1.05-6.39)$ relative to normal weight women. The odds of being obese were also found to be higher among women with any prior exposure to emotional violence $(\mathrm{aOR}=2.22 ; 95 \% \mathrm{Cl}=1.16-4.13)$. Interestingly, the adjusted odds of being obese were lower among women who had ever experienced any emotional or sexual violence $(\mathrm{aOR}=0.37 ; 95 \% \mathrm{Cl}=0.18-0.73)$.

\section{Dicussion}

This is the first study to explore the association between Zimbabwean women's exposure to IPV and nutritional status using ZDHS data collected from 2005-2015. Although prior studies in Zimbabwe have examined trends in prevalence of overweight and obesity [33] as well as associations between demographic characteristics, socioeconomic status and IPV against women [1], no study has investigated the complex relationship between IPV and nutritional status (i.e., underweight, overweight, and obesity) of women in the country. Moreover, the prevalence of both IPV and overweight is high in Zimbabwe $[1,33,54,55]$, which makes the country an appropriate setting for this study.

Overall, the findings revealed that more than one-third (43\%) of women reported to have ever experienced at least one form of intimate partner violence, which is higher than the global estimated prevalence of $30 \%[1,56]$. Nevertheless, this finding is consistent with previous studies in Zimbabwe [1, 54, 57-59] and other Sub-Saharan African countries $[60,61]$. Some of the risks for the high and increasing prevalence of IPV in developing countries have been attributed to cohabitation [62], rural residence $[63,64]$ and low economic status [65-67]. Poverty on the other hand has been shown to be a determinant of IPV $[68,69]$ as poor women tend to heavily depend on their partners $[66,69,70]$, which may limit their bargaining powers.

Regarding the various forms of IPV, we found emotional and sexual violence to be the most popular forms of violence against women $[54,58]$. Sexual violence may be low due to underreporting of such abuses in Africa [64, 71], stemming from traditional norms and beliefs [72].

The findings further revealed that women of reproductive age are at high risk of excess weight [31, 73, 74], as more than one-fifth reported being overweight and about $12 \%$ obese. Several studies have reported overweight and obesity to be on the rise in developing countries [29, 31, 33], and risk factors such as high economic status, urban residence $[75,76]$, and, indeed, intimate partner violence $[77,78]$ have been implicated.

Both intimate partner violence against women and obesity are growing health problems in low and middle-income countries (LMICs) [29-31, 49, 61, 73, 78]. Our findings showed that women who had ever experienced any form of IPV were more likely to be obese. Prior studies suggest that women who have been exposed to violence may experience negative psychological impacts [79, 80], which can lead to unhealthy food consumption and obesity [18]. Obesity affects women's participation in daily routines and 
other physical activities [81-83] which can affect their participation in the labour market [80], and also impact on other health outcomes [79, 84].

Surprisingly, we did not find any significant association between IPV and underweight, relative to normal weight. While this finding is consistent with some studies [74, 85], others suggest that exposure to IPV increases the odds of being underweight $[85,86]$. These inconsistent findings may be attributed to study population, demographic and socioeconomic contexts $[18,26,85]$. Meanwhile, the positive association between IPV and underweight has been associated with dietary behaviours characterized by substance abuse, insufficient calorie intake, or reduced food intake [26]. Furthermore, abusive partners may withhold food from victims, as a form of punishment which can negatively affect their weight $[18,26]$.

IPV and poor nutrition (underweight and overweight) are major determinants of health [87, 88], especially among women of reproductive age $[89,90]$. While obesity has been shown to be a risk factor for noncommunicable diseases such as diabetes and hypertension [91-93], IPV has been linked with mental health problems including traumatic stress $[15,94,95]$ and injury $[5,20,96]$. These findings, including the results presented in the current study, should be taken into account for the development of policies aiming for the promotion of peace and security of women. Such policies need to address gender related health issues as well as opportunities and pathways to reduce gender inequity and gendered social and health problems including IPV.

\section{Strengths and limitations}

The major strength of this study was that a nationally representative sample was used, where participants were sampled using probability sampling methods [59]. The range of relevant questions in the survey allowed for a detailed assessment of the IPV-obesity link in a large sample of women from Zimbabwe. Nonetheless, there are some limitations. First, due to the cross-sectional design of the DHS data, causality of associations between variables cannot be established. Longitudinal studies on exposure to IPV and the association with adverse health outcomes would be better suited for causal interpretation, although the currently available survey data already provide some convincing insights into the problem under investigation. Second, it has been shown that exposure to violence during childhood may increase subsequent exposures at adulthood [77, 97, 98], which may lead to excess weight. However, the study lacks data on violence experienced during childhood. Finally, it is likely that IPV reporting is hampered by issues of privacy, shame etc. This leads to information bias, and additional approaches to validate and enhance information on IPV experiences need to be considered [99-101].

\section{Conclusion}

The study findings showed that women of reproductive age in Zimbabwe are at high risk of both IPV and excess weight. Moreover, we found a positive relationship between IPV and obesity. Public health interventions that target the well-being, empowerment, and development of women are needed to address the complex issue of IPV and adverse health outcomes, including obesity. Legal, social and health institutions should collaborate to develop and implement appropriate intervention measures. 


\section{Abbreviations}

BMI- Body Mass Index

Cl- Confidence Intervals

CT- Conflict Tactics

DHS- Demographic Health Survey

EAs- Enumeration Areas

IPV- Intimate Partner Violence

LMIC- Low and Middle-Income Countries

OR- Odd Ratio

UNICEF- United Nations Children's Fund

WHO- World Health Organisation

ZDHS- Zimbabwe Demographic and Health Survey

\section{Declarations}

\section{Acknowledgments}

No acknowledgments to be made

\section{Author information}

\section{Affiliations}

Institute of Peace, Leadership and Governance, Africa University, Zimbabwe

Jeanette Iman'ishimwe Mukamana and Pamela Machakanja

Leibniz Institute for Prevention Research and Epidemiology - BIPS, Germany

Nicholas Kofi Adjei and Hajo Zeeb

Health Sciences Bremen, University of Bremen, Germany

Nicholas Kofi Adjei and Hajo Zeeb 
School of International Development and Global Studies, Faculty of Social Sciences, University of Ottawa, Canada

Sanni Yaya

\section{Funding}

There was no funding source

\section{Availability of data and materials}

The data used for this study came from the Demographic and Health Survey (DHS). Detailed information on the survey design and characteristics are provided on the DHS homepage, https://dhsprogram.com/Data/

\section{Author Contribution}

MIJ and NKA conceived the study. MIJ carried out extensive literature review and performed the statistical analysis with NKA. MIJ drafted the manuscript. MIJ, NKA, HZ, PM and SY critically revised and reviewed the manuscript. All authors read and approved the final manuscript.

\section{Competing interests}

The authors declare that they have no competing interests.

\section{Consent for publication}

Not applicable

\section{Ethical consideration}

The study was based on the secondary dataset with no identified information on the participants. The authors were granted approval from DHS Review Board to obtain and use the collected data for analysis.

\section{References}

1. Iman'ishimwe Mukamana J, Machakanja P, Adjei NK. Trends in prevalence and correlates of intimate partner violence against women in Zimbabwe, 2005-2015. BMC International Health and Human Rights. 2020;20: 2. doi:10.1186/s12914-019-0220-8

2. Garcia-Moreno C, Jansen HA, Ellsberg M, Heise L, Watts $\mathrm{CH}$. Prevalence of intimate partner violence: findings from the WHO multi-country study on women's health and domestic violence. The Lancet. 2006;368: 1260-1269. doi:10.1016/S0140-6736(06)69523-8

3. Uthman OA, Lawoko S, Moradi T. Factors associated with attitudes towards intimate partner violence against women: a comparative analysis of 17 sub-Saharan countries. BMC International Health and 
Human Rights. 2009;9: 14. doi:10.1186/1472-698X-9-14

4. Goodman LA, Koss MP, Felipe Russo N. Violence against women: Physical and mental health effects. Part I: Research findings. Applied and Preventive Psychology. 1993;2: 79-89. doi:10.1016/s09621849(05)80114-3

5. Black MC. Intimate Partner Violence and Adverse Health Consequences: Implications for Clinicians. American Journal of Lifestyle Medicine. 2011;5: 428-439. doi:10.1177/1559827611410265

6. The Five Types of Intimate Partner Violence. In: Elite Learning [Internet]. 1 Dec 2014 [cited 6 Nov 2019]. Available: https://www.elitecme.com/resource-center/nursing/five-types-intimate-partnerviolence/

7. Krug EG, Mercy JA, Dahlberg LL, Zwi AB. The world report on violence and health. The Lancet. 2002;360: 1083-1088. doi:10.1016/S0140-6736(02)11133-0

8. Joel Yager MD. Intimate Partner Violence Can Take Many Forms. NEJM Journal Watch. 2018;2018. doi:10.1056/nejm-jw.NA46613

9. pubmeddev, al AZ et. Income, Gender, and Forms of Intimate Partner Violence. - PubMed - NCBI. [cited 6 Nov 2019]. Available: https://www.ncbi.nlm.nih.gov/pubmed/29294851

10. García-Moreno C, Jansen H a. FM, Ellsberg M, Heise L, Watts C. WHO multi-country study on women's health and domestic violence against women: initial results on prevalence, health outcomes and women's responses. WHO multi-country study on women's health and domestic violence against women: initial results on prevalence, health outcomes and women's responses. 2005 [cited 26 Sep 2018]. Available: https://www.cabdirect.org/cabdirect/abstract/20063002089

11. Saunders DG. Are Physical Assaults by Wives and Girlfriends a Major Social Problem?: A Review of the Literature. Violence Against Women. 2002;8: 1424-1448. doi:10.1177/107780102237964

12. Bott S, Morrison A, Ellsberg M. Preventing and responding to gender-based violence in middle and low-income countries: a global review and analysis. The World Bank; 2005 Jun p. 1. Report No.: WPS3618. Available:

http://documents.worldbank.org/curated/en/852691468140377416/Preventing-and-responding-togender-based-violence-in-middle-and-low-income-countries-a-global-review-and-analysis

13. What Works to Prevent Partner Violence? An Evidence Overview I STRIVE. [cited 6 Dec 2019]. Available: http://strive.Ishtm.ac.uk/resources/what-works-prevent-partner-violence-evidence-overview

14. Bott S, Guedes A, Ruiz-Celis AP, Mendoza JA. Intimate partner violence in the Americas: a systematic review and reanalysis of national prevalence estimates. Rev Panam Salud Publica. 2019;43. doi:10.26633/RPSP.2019.26

15. Coker AL, Smith PH, Bethea L, King MR, McKeown RE. Physical health consequences of physical and psychological intimate partner violence. Arch Fam Med. 2000;9: 451-457.

16. Åsling-Monemi K, Peña R, Ellsberg MC, Persson LÅ. Violence against women increases the risk of infant and child mortality: a case-referent study in Nicaragua. Bull World Health Organ. 2003;81: 1016. doi:10.1590/S0042-96862003000100004 
17. Ferreira M de F, Moraes CL de, Reichenheim ME, Verly Junior E, Marques ES, Salles-Costa R. Effect of physical intimate partner violence on body mass index in low-income adult women. Cad Saúde Pública. 2015;31: 161-172. doi:10.1590/0102-311X00192113

18. Yount KM, Li L. Domestic Violence and Obesity in Egyptian Women. Journal of Biosocial Science. 2011;43: 85-99. doi:10.1017/S0021932010000441

19. Profiling Domestic Violence; A Multi-Country Study (English). [cited 28 Nov 2019]. Available: https://www.dhsprogram.com/publications/publication-od31-other-documents.cfm

20. Campbell J, Jones AS, Dienemann J, Kub J, Schollenberger J, O'Campo P, et al. Intimate Partner Violence and Physical Health Consequences. Arch Intern Med. 2002;162: 1157-1163. doi:10.1001/archinte.162.10.1157

21. Campbell JC. Health consequences of intimate partner violence. THE LANCET. 2002;359: 6.

22. CAMPBELL JC, SOEKEN KL. Forced Sex and Intimate Partner Violence: Effects on Women's Risk and Women's Health. Violence Against Women. 1999;5: 1017-1035. doi:10.1177/1077801299005009003

23. Bonomi AE, Thompson RS, Anderson M, Reid RJ, Carrell D, Dimer JA, et al. Intimate Partner Violence and Women's Physical, Mental, and Social Functioning. American Journal of Preventive Medicine. 2006;30: 458-466. doi:10.1016/j.amepre.2006.01.015

24. Ellsberg M, Jansen HAFM, Heise L, Watts CH, Garcia-Moreno C, WHO Multi-country Study on Women's Health and Domestic Violence against Women Study Team. Intimate partner violence and women's physical and mental health in the WHO multi-country study on women's health and domestic violence: an observational study. Lancet. 2008;371: 1165-1172. doi:10.1016/S01406736(08)60522-X

25. Jewkes R, Morrell R. Gender and sexuality: emerging perspectives from the heterosexual epidemic in South Africa and implications for HIV risk and prevention. J Int AIDS Soc. 2010;13: 6. doi:10.1186/1758-2652-13-6

26. Ackerson LK, Subramanian SV. Domestic violence and chronic malnutrition among women and children in India. Am J Epidemiol. 2008;167: 1188-1196. doi:10.1093/aje/kwn049

27. Sethuraman K, Lansdown R, Sullivan K. Women's Empowerment and Domestic Violence: The Role of Sociocultural Determinants in Maternal and Child Undernutrition in Tribal and Rural Communities in South India. Food Nutr Bull. 2006;27: 128-143. doi:10.1177/156482650602700204

28. Dutton MA, Green BL, Kaltman SI, Roesch DM, Zeffiro TA, Krause ED. Intimate Partner Violence, PTSD, and Adverse Health Outcomes. Journal of Interpersonal Violence. 2006;21: 955-968. doi:10.1177/0886260506289178

29. Kan K, Tsai W-D. Obesity and risk knowledge. Journal of Health Economics. 2004;23: 907-934. doi:10.1016/j.jhealeco.2003.12.006

30. Friedrich MJ. Global Obesity Epidemic Worsening. JAMA. 2017;318: 603-603. doi:10.1001/jama.2017.10693 
31. Abubakari AR, Lauder W, Agyemang C, Jones M, Kirk A, Bhopal RS. Prevalence and time trends in obesity among adult West African populations: a meta-analysis. Obes Rev. 2008;9: 297-311. doi:10.1111/j.1467-789X.2007.00462.x

32. Ng M, Fleming T, Robinson M, Thomson B, Graetz N, Margono C, et al. Global, regional, and national prevalence of overweight and obesity in children and adults during 1980-2013: a systematic analysis for the Global Burden of Disease Study 2013. Lancet. 2014;384: 766-781. doi:10.1016/S01406736(14)60460-8

33. Mukora-Mutseyekwa F, Zeeb H, Nengomasha L, Adjei N. Trends in prevalence \& determinants of overweight \& obesity among women of reproductive age in Zimbabwe, 2005-2015. 2019.

34. Lincoln KD, Abdou CM, Lloyd D. Race and Socioeconomic Differences in Obesity and Depression among Black and Non-Hispanic White Americans. J Health Care Poor Underserved. 2014;25: 257275. doi:10.1353/hpu.2014.0038

35. Seematter G, Dirlewanger M, Rey V, Schneiter P, Tappy L. Metabolic effects of mental stress during over- and underfeeding in healthy women. Obes Res. 2002;10: 49-55. doi:10.1038/oby.2002.7

36. Huang HY, Yang W, Omaye ST. Intimate partner violence, depression and overweight/obesity. Aggression and Violent Behavior. 2011;16: 108-114. doi:10.1016/j.avb.2010.12.005

37. Alvarez J, Pavao J, Baumrind N, Kimerling R. The Relationship Between Child Abuse and Adult Obesity Among California Women. American Journal of Preventive Medicine. 2007;33: 28-33. doi:10.1016/j.amepre.2007.02.036

38. Johnson PJ, Hellerstedt WL, Pirie PL. Abuse history and nonoptimal prenatal weight gain. Public Health Rep. 2002;117: 148-156. doi:10.1093/phr/117.2.148

39. Boy A, Salihu HM. Intimate partner violence and birth outcomes: a systematic review. Int J Fertil Womens Med. 2004;49: 159-164.

40. Irie M, Asami S, Nagata S, Miyata M, Kasai H. Relationships between perceived workload, stress and oxidative DNA damage. Int Arch Occup Environ Health. 2001;74: 153-157.

doi:10.1007/s004200000209

41. Hapuarachchi JR, Chalmers AH, Winefield AH, Blake-Mortimer JS. Changes in clinically relevant metabolites with psychological stress parameters. Behav Med. 2003;29: 52-59. doi:10.1080/08964280309596057

42. Epel ES, Blackburn EH, Lin J, Dhabhar FS, Adler NE, Morrow JD, et al. From the Cover: Accelerated telomere shortening in response to life stress. Proceedings of the National Academy of Sciences of the United States of America. 2004;101: 17312. doi:10.1073/pnas.0407162101

43. Raj A, Livramento KN, Santana MC, Gupta J, Silverman JG. Victims of intimate partner violence more likely to report abuse from in-laws. Violence Against Women. 2006;12: 936-949. doi:10.1177/1077801206292935

44. Stephenson R, Koenig MA, Ahmed S. Domestic violence and symptoms of gynecologic morbidity among women in North India. Int Fam Plan Perspect. 2006;32: 201-208. doi:10.1363/ifpp.32.201.06 
45. WHO I Global status report on noncommunicable diseases 2014. In: WHO [Internet]. [cited 21 Oct 2018]. Available: http://www.who.int/nmh/publications/ncd-status-report-2014/en/

46. Mathew AE, Marsh B, Smith LS, Houry D. Association between Intimate Partner Violence and Health Behaviors of Female Emergency Department Patients. Western Journal of Emergency Medicine. 2012;13: 278. doi:10.5811/westjem.2012.3.11747

47. Mufunda E, Makuyana L. Mufunda, E . and Makuyana, L. (2016) Obesity: a potential pandemic among the youths in zimbabwe. Journal of Diabetes Mellitus , $6,136-145$. Journal of Diabetes Mellitus , 6 , 136- 145. 2016;6: 136-145. doi:10.4236/jdm.2016.62014

48. Barao K, Forones NM. Body mass index: different nutritional status according to WHO, OPAS and Lipschitz classifications in gastrointestinal cancer patients. Arquivos de Gastroenterologia. 2012;49: 169-171. doi:10.1590/S0004-28032012000200013

49. Obesity: preventing and managing the global epidemic: report of a WHO consultation. [cited 21 Oct 2018]. Available: http://apps.who.int/iris/handle/10665/42330

50. Obesity. [cited 3 Jul 2020]. Available: https://www.who.int/westernpacific/health-topics/obesity

51. WHO / Obesity: preventing and managing the global epidemic. In: WHO [Internet]. World Health Organization; [cited 9 Jun 2020]. Available: http://www.who.int/entity/nutrition/publications/obesity/WHO_TRS_894/en/index.html

52. STRAUS MA, HAMBY SL, BONEY-McCOY S, SUGARMAN DB. The Revised Conflict Tactics Scales (CTS2): Development and Preliminary Psychometric Data. Journal of Family Issues. 1996;17: 283316. doi:10.1177/019251396017003001

53. WHO | Putting women first: Ethical and safety recommendations for research on domestic violence against women. [cited 23 Oct 2018]. Available: https://www.who.int/gender-equityrights/knowledge/who_fch_gwh_01.1/en/

54. Shamu S, Zarowsky C, Roelens K, Temmerman M, Abrahams N. High-frequency intimate partner violence during pregnancy, postnatal depression and suicidal tendencies in Harare, Zimbabwe. General Hospital Psychiatry. 2016;38: 109-114. doi:10.1016/j.genhosppsych.2015.10.005

55. Biadgilign S, Mgutshini T, Haile D, Gebremichael B, Moges Y, Tilahun K. Epidemiology of obesity and overweight in sub-Saharan Africa: a protocol for a systematic review and meta-analysis. BMJ Open. 2017;7: e017666. doi:10.1136/bmjopen-2017-017666

56. WHO I Global and regional estimates of violence against women. In: WHO [Internet]. [cited 15 Sep 2018]. Available: http://www.who.int/reproductivehealth/publications/violence/9789241564625/en/

57. Fidan A, Bui HN. Intimate Partner Violence Against Women in Zimbabwe: Violence Against Women. 2015 [cited 8 Jul 2020]. doi:10.1177/1077801215617551

58. Ezechi OC, Kalu BK, Ezechi LO, Nwokoro CA, Ndububa VI, Okeke GCE. Prevalence and pattern of domestic violence against pregnant Nigerian women. Journal of Obstetrics and Gynaecology. 2004;24: 652-656. doi:10.1080/01443610400007901

59. Agency ZNS, International ICF. Zimbabwe Demographic and Health Survey 2015: Final Report. 2016 [cited 16 Sep 2018]. Available: https://dhsprogram.com/publications/publication-fr322-dhs-final- 
reports.cfm

60. Global and regional estimates of violence against women: prevalence and health effects of intimate partner violence and non-partner sexual violence. Geneva: World Health Organization, Department of Reproductive Health and Research; 2013.

61. Garcia-Moreno C, Jansen HAFM, Ellsberg M, Heise L, Watts CH, WHO Multi-country Study on Women's Health and Domestic Violence against Women Study Team. Prevalence of intimate partner violence: findings from the WHO multi-country study on women's health and domestic violence. Lancet. 2006;368: 1260-1269. doi:10.1016/S0140-6736(06)69523-8

62. Jackson NA. Observational experiences of intrapersonal conflict and teenage victimization: A comparative study among spouses and cohabitors. Journal of Family Violence. 1996;11: 191-203. doi:10.1007/BF02336940

63. Ajah LO, lyoke CA, Nkwo PO, Nwakoby B, Ezeonu P. Comparison of domestic violence against women in urban versus rural areas of southeast Nigeria. International Journal of Women's Health. 2014;6: 865. doi:10.2147/IJWH.S70706

64. Hindin MJ. Understanding women's attitudes towards wife beating in Zimbabwe. Bull World Health Organ, Bull World Health Organ. 2003;81: 501-508. doi:10.1590/S0042-96862003000700008

65. Hornung CA, McCullough BC, Sugimoto T. Status Relationships in Marriage: Risk Factors in Spouse Abuse. Journal of Marriage and Family. 1981;43: 675-692. doi:10.2307/351768

66. Cunradi CB, Caetano R, Clark C, Schafer J. Neighborhood Poverty as a Predictor of Intimate Partner Violence Among White, Black, and Hispanic Couples in the United States: A Multilevel Analysis. Annals of Epidemiology. 2000;10: 297-308. doi:10.1016/S1047-2797(00)00052-1

67. Lawoko S, Dalal K, Jiayou L, Jansson B. Social Inequalities in Intimate Partner Violence: A Study of Women in Kenya. Violence and Victims. 2007;22: 773-784. doi:10.1891/088667007782793101

68. YLLÖ K. Sexual Equality and Violence Against Wives in American States. Journal of Comparative Family Studies. 1983;14: 67-86. Available: https://www.jstor.org/stable/41601328

69. Heise LL. Determinants of partner violence in low and middle-income countries: exploring variation in individual and population-level risk. doctoral, London School of Hygiene \& Tropical Medicine. 2012. Available: http://researchonline.lshtm.ac.uk/682451/

70. Vyas S, Watts C. How does economic empowerment affect women's risk of intimate partner violence in low and middle income countries? A systematic review of published evidence. Journal of International Development. 2009;21: 577-602. doi:10.1002/jid.1500

71. Dobash RE, Dobash RP. Wives: The appropriate victims of marital violence. Victimology. 1977;2: 426-442.

72. Jewkes R, Morrell R. Sexuality and the limits of agency among South African teenage women: theorising femininities and their connections to HIV risk practices. Soc Sci Med. 2012;74: 17291737. doi:10.1016/j.socscimed.2011.05.020

73. Mitchell N, Catenacci V, Wyatt HR, Hill JO. OBESITY: OVERVIEW OF AN EPIDEMIC. Psychiatr Clin North Am. 2011;34: 717-732. doi:10.1016/j.psc.2011.08.005 
74. Davies R, Lehman E, Perry A, McCall-Hosenfeld JS. Association of intimate partner violence and health-care provider-identified obesity. Women \& Health. 2016;56: 561-575.

doi:10.1080/03630242.2015.1101741

75. Herald T. Is Zimbabwe sliding towards obesity? In: The Herald [Internet]. [cited 7 Nov 2019]. Available: https://www.herald.co.zw/is-zimbabwe-sliding-towards-obesity/

76. Chronicle T. A fat nation: Urban Zimbabwe's descent to obesity. In: The Chronicle [Internet]. [cited 7 Nov 2019]. Available: https://www.chronicle.co.zw/a-fat-nation-urban-zimbabwes-descent-toobesity/

77. Midei AJ, Matthews KA. Interpersonal violence in childhood as a risk factor for obesity: a systematic review of the literature and proposed pathways. Obes Rev. 2011;12: e159-172. doi:10.1111/j.1467789X.2010.00823.x

78. Bosch J, Weaver TL, Arnold LD, Clark EM. The Impact of Intimate Partner Violence on Women's Physical Health: Findings From the Missouri Behavioral Risk Factor Surveillance System. J Interpers Violence. 2017;32: 3402-3419. doi:10.1177/0886260515599162

79. Gordon-Larsen P. Obesity-Related Knowledge, Attitudes, and Behaviors in Obese and Non-obese Urban Philadelphia Female Adolescents. Obesity Research. 2001;9: 112-118. doi:10.1038/oby.2001.14

80. DiBonaventura M, Lay AL, Kumar M, Hammer M, Wolden ML. The Association Between Body Mass Index and Health and Economic Outcomes in the United States. J Occup Environ Med. 2015;57: 1047-1054. doi:10.1097/JOM.0000000000000539

81. Pudrovska T, Reither EN, Logan ES, Sherman-Wilkins KJ. Gender and reinforcing associations between socioeconomic disadvantage and body mass over the life course. J Health Soc Behav. 2014;55: 283-301. doi:10.1177/0022146514544525

82. Conklin Al, Forouhi NG, Suhrcke M, Surtees P, Wareham NJ, Monsivais P. Socioeconomic status, financial hardship and measured obesity in older adults: a cross-sectional study of the EPIC-Norfolk cohort. BMC Public Health. 2013;13: 1039. doi:10.1186/1471-2458-13-1039

83. Hiilamo A, Lallukka T, Mänty M, Kouvonen A. Obesity and socioeconomic disadvantage in midlife female public sector employees: a cohort study. BMC Public Health. 2017;17: 842. doi:10.1186/s12889-017-4865-8

84. Djalalinia S, Qorbani M, Peykari N, Kelishadi R. Health impacts of Obesity. Pak J Med Sci. 2015;31: 239-242. doi:10.12669/pjms.311.7033

85. Ferdos J, Rahman M, Ferdos J, Rahman M. Exposure to intimate partner violence and malnutrition among young adult Bangladeshi women: cross-sectional study of a nationally representative sample. Cadernos de Saúde Pública. 2018;34. doi:10.1590/0102-311x00113916

86. Sivonová M, Zitnanová I, Hlincíková L, Skodácek I, Trebatická J, Duracková Z. Oxidative stress in university students during examinations. Stress. 2004;7: 183-188.

doi:10.1080/10253890400012685

Page 21/23 
87. Adhikari RP, Yogi S, Acharya A, Cunningham K. Intimate partner violence and nutritional status among nepalese women: an investigation of associations. BMC Womens Health. 2020;20: 127. doi:10.1186/s12905-020-00991-x

88. Rahman M, Nakamura K, Seino K, Kizuki M. Intimate partner violence and chronic undernutrition among married Bangladeshi women of reproductive age: are the poor uniquely disadvantaged? Eur $\mathrm{J}$ Clin Nutr. 2013;67: 301-307. doi:10.1038/ejcn.2012.202

89. Willie TC, Kershaw TS, Callands TA. Examining relationships of intimate partner violence and food insecurity with HIV-related risk factors among young pregnant Liberian women. AIDS Care. 2018;30: 1156-1160. doi:10.1080/09540121.2018.1466983

90. Diamond-Smith N, Conroy AA, Tsai AC, Nekkanti M, Weiser SD. Food insecurity and intimate partner violence among married women in Nepal. J Glob Health. 2019;9: 010412. doi:10.7189/jogh.09.010412

91. Oğuz A, Temizhan A, Abaci A, Kozan O, Erol C, Ongen Z, et al. Obesity and abdominal obesity; an alarming challenge for cardio-metabolic risk in Turkish adults. Anadolu Kardiyol Derg. 2008;8: 401406.

92. Pi-Sunyer X. The Medical Risks of Obesity. Postgrad Med. 2009;121: 21-33. doi:10.3810/pgm.2009.11.2074

93. Rubenstein AH. Obesity: a modern epidemic. Trans Am Clin Climatol Assoc. 2005;116: 103-111; discussion 112-113.

94. Tjaden P, Thoennes N. Prevalence and consequences of male-to-female and female-to-male intimate partner violence as measured by the National Violence Against Women Survey. Violence Against Women. 2000;6: 142-161. doi:10.1177/10778010022181769

95. Goodman LA, Koss MP, Felipe Russo N. Violence against women: Physical and mental health effects. Part I: Research findings. Applied and Preventive Psychology. 1993;2: 79-89. doi:10.1016/S09621849(05)80114-3

96. Breiding MJ, Black MC, Ryan GW. Chronic Disease and Health Risk Behaviors Associated with Intimate Partner Violence-18 U.S. States/Territories, 2005. Annals of Epidemiology. 2008;18: 538544. doi:10.1016/j.annepidem.2008.02.005

97. Alhalal E. Obesity in women who have experienced intimate partner violence. Journal of Advanced Nursing. 2018;74: 2785-2797. doi:10.1111/jan.13797

98. Whitaker RC, Phillips SM, Orzol SM, Burdette HL. The association between maltreatment and obesity among preschool children. Child Abuse \& Neglect. 2007;31: 1187-1199. doi:10.1016/j.chiabu.2007.04.008

99. Testa M, Livingston JA, VanZile-Tamsen C. ADVANCING THE STUDY OF VIOLENCE AGAINST WOMEN USING MIXED METHODS: INTEGRATING QUALITATIVE METHODS INTO A QUANTITATIVE RESEARCH PROGRAM. Violence Against Women. 2011;17: 236-250.

doi:10.1177/1077801210397744 
100. Matthews S. Crafting Qualitative Research Articles on Marriages and Families. Journal of Marriage and the Family. 2005;67: 799-808. doi:10.1111/j.1741-3737.2005.00176.x

101. Ruiz-Pérez I, Plazaola-Castaño J, Vives-Cases C. Methodological issues in the study of violence against women. J Epidemiol Community Health. 2007;61: ii26-ii31. doi:10.1136/jech.2007.059907

\section{Figures}

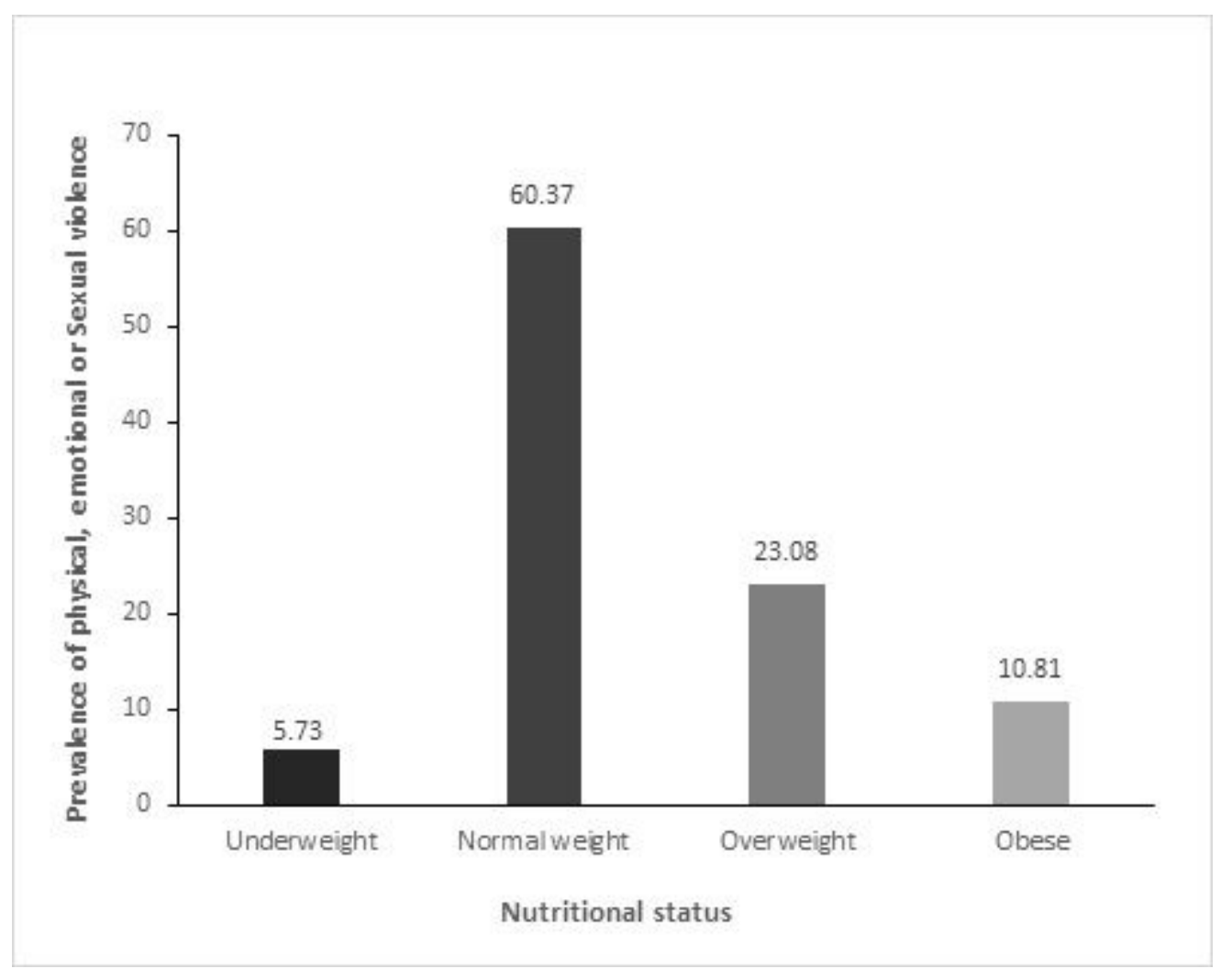

Figure 1

Prevalence of physical, emotional or sexual violence against women of reproductive age (15-49 years) by nutritional status, Zimbabwe, pooled data, 2005-2015. 